\title{
EXAMINING THE ADEQUACY OF SEPARATION GAPS BETWEEN ADJACENT BUILDINGS UNDER NEAR-FIELD AND FAR-FIELD EARTHQUAKES
}

\author{
YAZAN JARADAT, HARRY FAR \& ALI SALEH \\ School of Civil and Environmental Engineering, Faculty of Engineering and Information Technology, \\ University of Technology Sydney (UTS), Australia
}

\begin{abstract}
Earthquake-induced pounding is a phenomenon that has been observed in almost every major earthquake since the 1960s. Pounding between adjacent buildings occurs due to insufficient separation and with different dynamic properties. This usually causes local damage, and in some extreme cases, total collapse of structures. Building codes in seismically active zones recommended a minimum separation gap between adjacent buildings to avoid pounding during severe earthquakes. AS1170.42007 is an Australian standard that requires 1\% of the building height as a minimum separation gap between buildings to preclude pounding. This article presents experimental and numerical results to examine the adequacy of this specification to avoid seismic pounding between steel-frame structures under near-field and far-field earthquakes. It is found that AS1170.4-2007 is inadequate if the shorter building is used to estimate the required separation between adjacent structures under both near-field and far-field earthquakes. The code specification is adequate if the taller building is used to estimate the required separation between adjacent structures under far-field earthquakes only. The results are also compared with corresponding results obtained using the ABS and SRSS methods.

Keywords: adjacent building, separation gap, steel frame, seismic code, SAP2000, shake table.
\end{abstract}

\section{INTRODUCTION}

Investigations have shown that collisions between adjacent buildings during earthquakes may cause severe structural damage. These collisions, generally called 'structural pounding', occur due to several factors such as insufficient separation between adjacent buildings and different dynamic characteristics, which cause an out-of-phase vibration [1].

The phenomenon of structural pounding has been observed in many earthquakes. Analysis of damage statistics show that pounding was present in over $40 \%$ of the 330 collapsed or severely damaged buildings during the 1985 Mexico earthquake, and for at least $15 \%$ of them pounding was the main cause for collapse [2]. Pounding damage was also observed in the San Francisco Bay area during the 1989 Loma Prieta earthquake; out of the 500 buildings surveyed, more than 200 showed damage caused by pounding [3]. Also, in the 1994 Northridge (US) earthquake and the 1995 Kobe (Japan) earthquake, damage due to pounding was observed [4].

Structural pounding is a complex phenomenon involving plastic deformations at contact points, local cracking or crushing, and fracturing due to impact and friction [5]. According to several researchers, the main reason for seismic pounding is insufficient separation gap between adjacent buildings [1], [6].

The effectiveness of different techniques to mitigate pounding have been presented in several studies; for example (1) the use of collision shear walls and bracing systems [7]; (2) the installation of soft material layers, such as rubber, at certain locations on adjacent buildings where pounding is expected [8]; and (3) connecting adjacent structures with links (such as spring links, dashpot links or viscoelastic links) to produce in-phase vibrations [6], [9]. 
However, the above methods have advantages and disadvantages. For example, using shear walls decreases the top displacements and number of impacts while increasing the maximum impact force; filling gaps with rubber pads may reduce peak impact force while increasing the number of poundings; and joining two structures is beneficial to the flexible adjacent structure while increasing the response of the stiffer building. Therefore, and based on the definition of pounding, providing a sufficiently large gap between adjacent buildings is the most common natural way to prevent structural pounding. It is concluded that the most effective method is to increase the separation distance to completely preclude pounding.

Building codes in zones of active seismicity around the world have recognised the destructive effects that pounding may induce. The approach commonly adopted in building codes has been to avoid contact interactions between structures by providing sufficient separation between them. In some cases, codes depend on the maximum displacements of each building only, while in other cases a small proportion of maximum displacement is used. In other cases, the separation distance depends on the building height, while still others adopt a combination of maximum displacement and building height. Furthermore, some codes depend on the type of soil and seismic action. Below are examples of various international codes. According to the 2009 edition of the International Building Code [10], minimum separations are given by:

$$
\begin{aligned}
& S=U_{a}+U_{b}, \\
& S=\sqrt{U_{a}{ }^{2}+U_{b}{ }^{2},}
\end{aligned}
$$

where $S$ is separation distance and $U_{a}, U_{b}$ are the maximum displacement responses of the adjacent structures "a" and "b", respectively, at the location where pounding is expected to occur (i.e. at the level coinciding with the roof level of the shorter building) [11]. Eqns (1) and (2) are usually referred to as the absolute sum ABS and SRSS rules (square root of sum of squares), respectively. The Uniform Building Code [12] also follows the same codal provisions. The National Building Code of Canada (NBCC) [13] requires the separation between adjacent structures or across construction joints to equal or exceed the value of

$$
S=\sqrt{U_{a}+U_{b}},
$$

in which $U_{a}, U_{b}$ are the maximum displacement responses of the adjacent structures "a" and "b", respectively, at the location where pounding is expected to occur. Additionally, Eurocode 8 [14] proposed stricter requirements, according to which the minimum separation distance $\mathrm{S}$ (in metres) between two adjacent buildings should be less than (a) $S=0.05+$ $0.005 h$ and (b) $S=0.4 q\left(u_{a}+u_{b}\right)$, where $h, q$ and $u_{a}, u_{b}$ are the building height (in metres), the behaviour factor, and the top floor displacement of the two buildings due to seismic design forces, respectively.

The Australian Earthquake Standard (AS1170.4-2007) [15] states that pounding needs to be considered for structures over $15 \mathrm{~m}$ for design category II or III. Clauses 5.4.5 and 5.5.5 for design category II and III states "this clause is deemed to be satisfied if the setback from a boundary is more than $1 \%$ of the structure height". Hao [16] rephrased the previous statement as that the required separation is equal to $1 \%$ of the adjacent building height, expressed in eqn (4).

$$
S=0.01 H
$$

where $H$ is the building height. 
The minimum required separation between adjacent structures to avoid pounding has been investigated by many authors. In previous studies, building structures are idealised as single-degree-of-freedom (SDOF) oscillators [17], [18] or multiple-degree-of-freedom (MDOF) oscillators [1], [19], [20] and structural responses are considered as either linear elastic or non-linear inelastic. All the above-mentioned researchers carried out functional research regarding earthquake-induced pounding between adjacent structures and the required separation distance to preclude pounding. These studies showed that an earthquake's impact depends on its epicentre. They distinguished two major types of earthquake motion: spatially varying ground motion and uniform motion. Spatially varying motion generates larger relative responses between adjacent structures than uniform motion; its effect is especially important in stiff low-rise adjacent structures.

This article examines the adequacy of the minimum separation gap prescribed by AS1170.4, to find out whether or not the minimum separation gap of $1 \%$ between two adjacent steel-frame structures is enough to preclude pounding under earthquake ground motion.

\section{EXPERIMENT}

\subsection{Description of test frames}

The experiment tested 1/30 scale single-bay moment resisting steel-frame models - as 15storey, 10-storey and 5-storey structures - on an MTS 354.20 multi-axial simulation table of size $2.2 \mathrm{~m} \times 2.2 \mathrm{~m}$ at the University of Technology, Sydney. This table is capable of testing samples of 2 tonnes at $5 \mathrm{~g}$ accelerations, $1,000 \mathrm{~mm} / \mathrm{s}$ velocity and up to $\pm 200 \mathrm{~mm}$ stroke. The three frame structures were designed individually, at their reduced scale, according to AS/NZS 3678-2011 (Structural Steel). The general arrangement of the three test frames, placed on the shake table, is shown in Fig. 1. The overall floor plan dimensions of all models are $0.4 \mathrm{~m} \times 0.4 \mathrm{~m}$. The height of the 15 -storey frame, 10 -storey frame and 5-storey frame are $1.5 \mathrm{~m}, 1.0 \mathrm{~m}$ and $0.5 \mathrm{~m}$, respectively. Columns and floors of the three models are made of rectangular flat steel sections of $40 \mathrm{~mm} \times 2 \mathrm{~mm}$ and $400 \mathrm{~mm} \times 5 \mathrm{~mm}$, respectively. More details are available in [21], [22].

\subsection{Preliminary system identification tests}

The dynamic characteristics of each steel frame were identified by conducting several preliminary tests: a free vibration test, stiffness test and sine sweep test. In the free vibration test, the experiment aimed to measure the fundamental period and damping of the structures. Experimentally, damping can be estimated by various methods, including one that uses the width of the peak value of the frequency response function of the structure [23]. In the stiffness test, the experiment aimed to measure the stiffness parameter for the frame structure. Finally, the purpose of a sine sweep test is to determine the natural frequency and modes of vibration, especially mode 1 , mode 2 and mode 3 , since a free vibration test cannot measure these modes. Tables 1 and 2 illustrate the dynamic characteristics of the experimental and numerical results for the 15-storey, 10 -storey and 5-storey models. Results are closely similar in natural period and stiffness. 


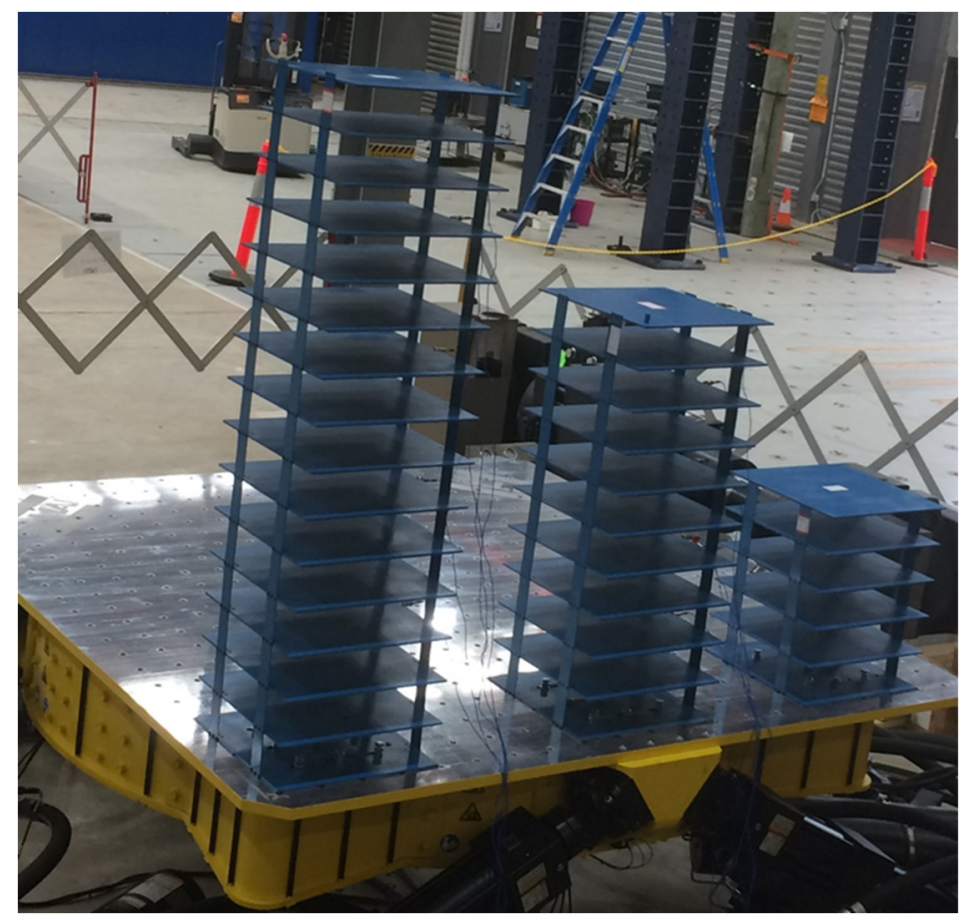

Figure 1: Test frames on shake table.

\subsection{Adopted earthquake acceleration records}

Four scaled earthquake acceleration records - El Centro 1940 (Fig. 2(a)), Hachinohe 1968 (Fig. 2(b)), Kobe 1995 (Fig. 2(c)) and Northridge 1994 (Fig. 2(d)) - were adopted for the shake table tests [22]. The first two earthquakes involved far-field ground motion, and the second two involved near-field motion. These earthquake records have been chosen by the International Association for Structural Control and Monitoring for benchmark seismic studies [24].

Structures behave differently during near-field compared to far-field earthquakes, and this behaviour should be considered in the design process of structures [25]. Several researchers reported the importance of the near-field ground motion characteristics on the elastic and inelastic dynamic behaviour of structures [26], [27].

Table 1: Experimental dynamic characteristics of the structural models.

\begin{tabular}{|l|c|c|c|c|c|c|}
\hline & \multicolumn{6}{|c|}{ Experimental } \\
\hline & \multicolumn{2}{|c|}{ Free vibration } & \multicolumn{3}{c|}{ Sine sweep test } & $\begin{array}{c}\text { Stiffness } \\
\mathrm{kN} / \mathrm{mm}\end{array}$ \\
\hline & Natural frequency & Damping & Mode 1 & Mode 2 & Mode 3 & \\
& $\mathrm{Hz}$ & $\%$ & $\mathrm{~Hz}$ & $\mathrm{~Hz}$ & $\mathrm{~Hz}$ & \\
\hline 5-storey & 6.53 & 0.467 & 7.05 & 21.15 & 36.83 & 0.0275 \\
\hline 10-storey & 3.54 & 0.431 & 3.61 & 11.26 & 18.70 & 0.0144 \\
\hline 15-storey & 2.27 & 0.503 & 2.33 & 7.11 & 11.76 & 0.0081 \\
\hline
\end{tabular}


Table 2: Numerical dynamic characteristics of the structural models.

\begin{tabular}{|l|c|c|c|c|}
\hline & \multicolumn{4}{|c|}{ Numerical } \\
\hline & \multicolumn{4}{|c|}{ Modal load analysis } \\
\hline & Mode 1 Hz & Mode 2 Hz & Mode 3 Hz & \\
\hline 5-storey & 6.76 & 20.31 & 33.24 & 0.0278 \\
\hline 10-storey & 3.53 & 10.57 & 17.56 & 0.0149 \\
\hline 15-storey & 2.29 & 6.87 & 11.44 & 0.0090 \\
\hline
\end{tabular}
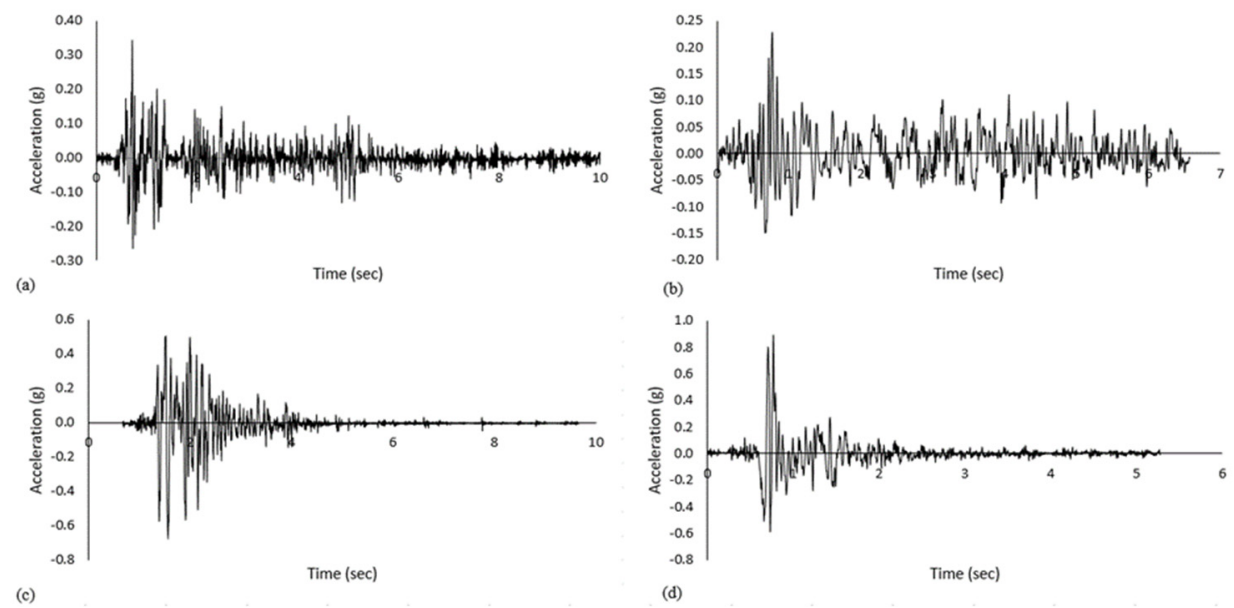

Figure 2: Scaled earthquake ground motion. (a) El Centro earthquake 1940; (b) Hachinohe earthquake 1968; (c) Kobe earthquake 1995; and (d) Northridge earthquake 1994.

Shake table tests were then performed on the 15-storey, 10-storey and 5-storey structural models, which were directly fixed on top of the shake table, to obtain seismic responses of the structural models to be used for numerical verification. After securing the structural models on the shake table as shown in Fig. 1, accelerometers were installed on each model. The arrangement of the accelerometers was as follows: for the 15-storey structural model, one on the fifth floor, one on the tenth floor and one on the fifteenth floor; for the 10-storey structural model, one on the fifth floor and one on the tenth floor; for the 5-storey structural model, one on the fifth floor only. In addition, a further accelerometer was mounted on the shake table. The acceleration time history recorded by this accelerometer was used as input ground motion in the numerical analyses, to eliminate reproduction errors. The models also had a significantly large separation gap to avoid pounding.

\section{DISCUSSION}

The software used for numerical investigation as a three-dimensional frame is known as SAP2000 version 20 [28]. It is appropriate for the output of time-history analysis with a nonlinear gap element, and specifically, to model pounding conditions and obtain structural responses such as displacement and acceleration. Ritz vector was selected as the mode type, in the modal load case [29]. The selected maximum numbers of modes were 99 and $99 \%$ 
target dynamic participation ratios. Non-linear dynamic analysis or fast non-linear analysis (FNA) were performed under the influence of the four scaled earthquake acceleration records with 9,000 time steps at $0.001 \mathrm{~s}$ step size, 5,500 time steps at $0.001 \mathrm{~s}$ step size, 10,000 time steps at $0.001 \mathrm{~s}$ step size, and 6,000 time steps with $0.001 \mathrm{~s}$ step size of the El Centro, Hachinohe, Kobe and Northridge earthquakes, respectively.

The numerical predictions and experimental values of the absolute acceleration time histories for the three structural frame models are presented and compared. It becomes apparent that the trend and the values of the experimental shake table test results are in good agreement and consistent with the numerical predictions. Numerical displacement was used, since the purpose of this experiment is to determine the minimum separation distance between adjacent structures to avoid pounding. In this article, only one structural frame model is shown (in Fig. 3). This is due to page limitations.
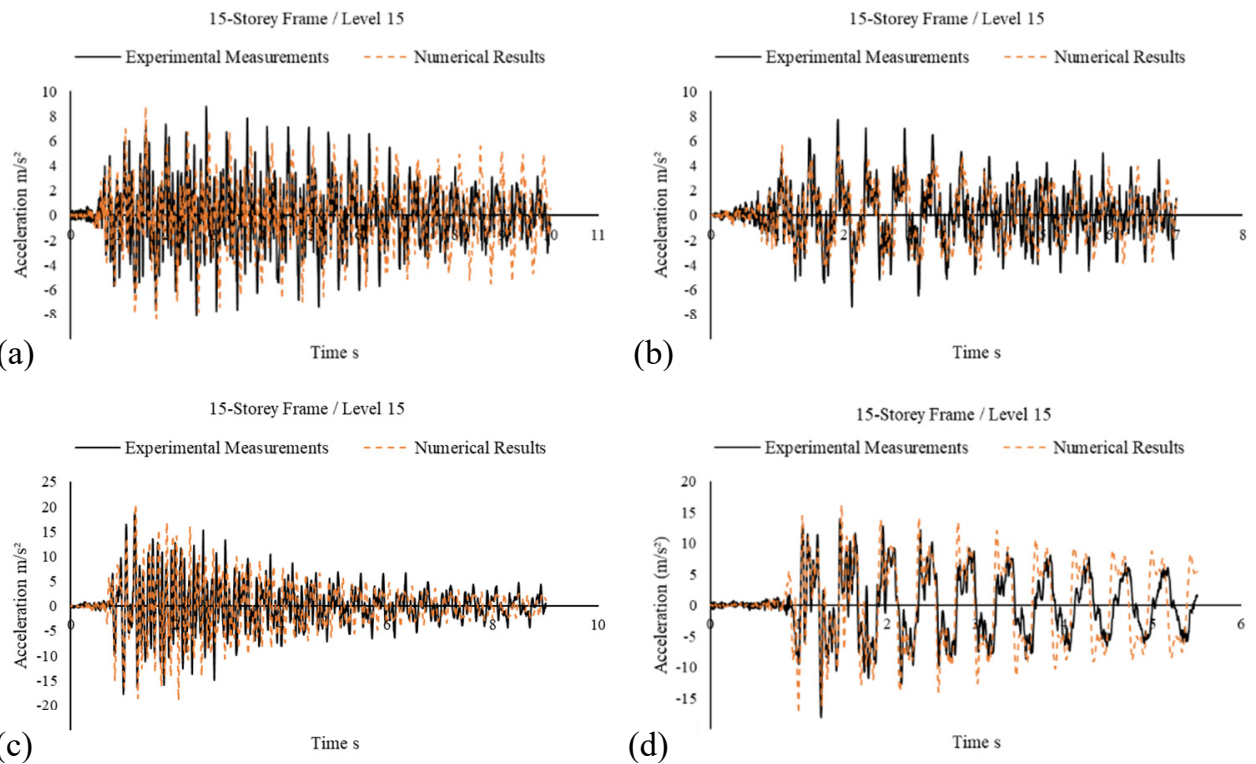

Figure 3: Experimental and numerical absolute acceleration time histories for 15-storey frame (top floor) under (a) Scaled El Centro earthquake; (b) Scaled Hachinohe earthquake; (c) Scaled Kobe earthquake; and (d) Scaled Northridge earthquake.

Top floor numerical relative displacement time histories for the 15-storey, 10 -storey and 5 -storey frames under scaled earthquake ground motion are discussed. Only the 15-storey frame is shown in Fig. 4. Relative displacement time histories under the four scaled seismic excitations are compared. For the top floor of the 15-storey frame. It can be seen that the highest relative displacement caused under the Northridge earthquake was $40.9 \mathrm{~mm}$. This displacement was $19.7 \mathrm{~mm}, 14.7 \mathrm{~mm}$ and $16.9 \mathrm{~mm}$ for Kobe, El Centro and Hachinohe, respectively. Top floor relative displacement time histories of the 10-storey frame under the four scaled seismic excitations showed the highest relative displacement under the Northridge earthquake, at $31.5 \mathrm{~mm}$, and $26.3 \mathrm{~mm}, 7.3 \mathrm{~mm}$ and $3.8 \mathrm{~mm}$ for Kobe, El Centro and Hachinohe, respectively. Relative displacement time histories for the top floor of the 


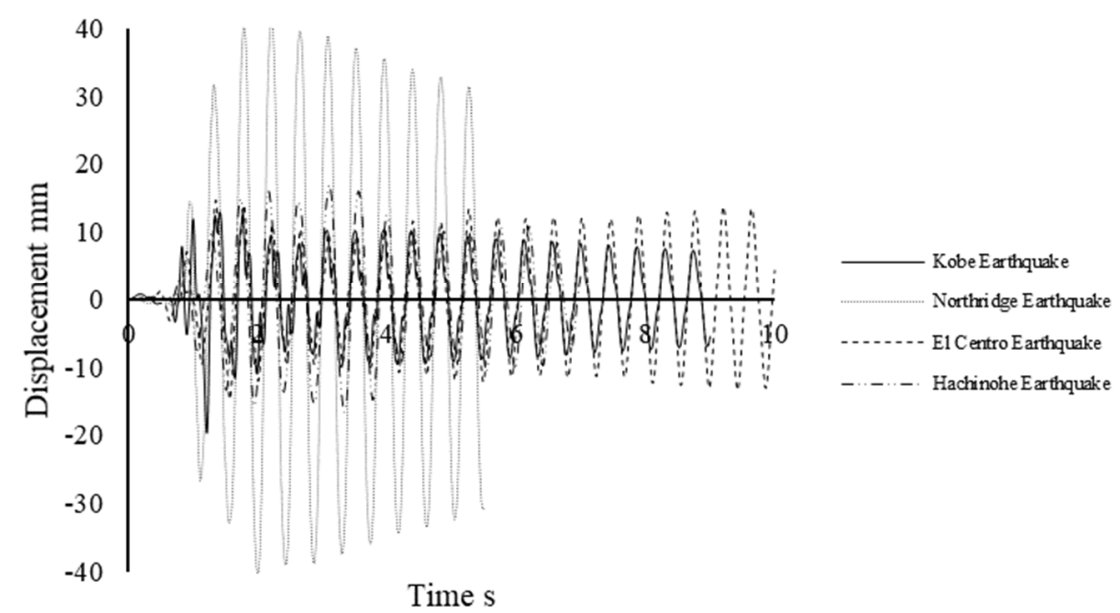

Figure 4: Top floor numerical relative displacement time histories of the 15-storey frame, under four scaled earthquakes.
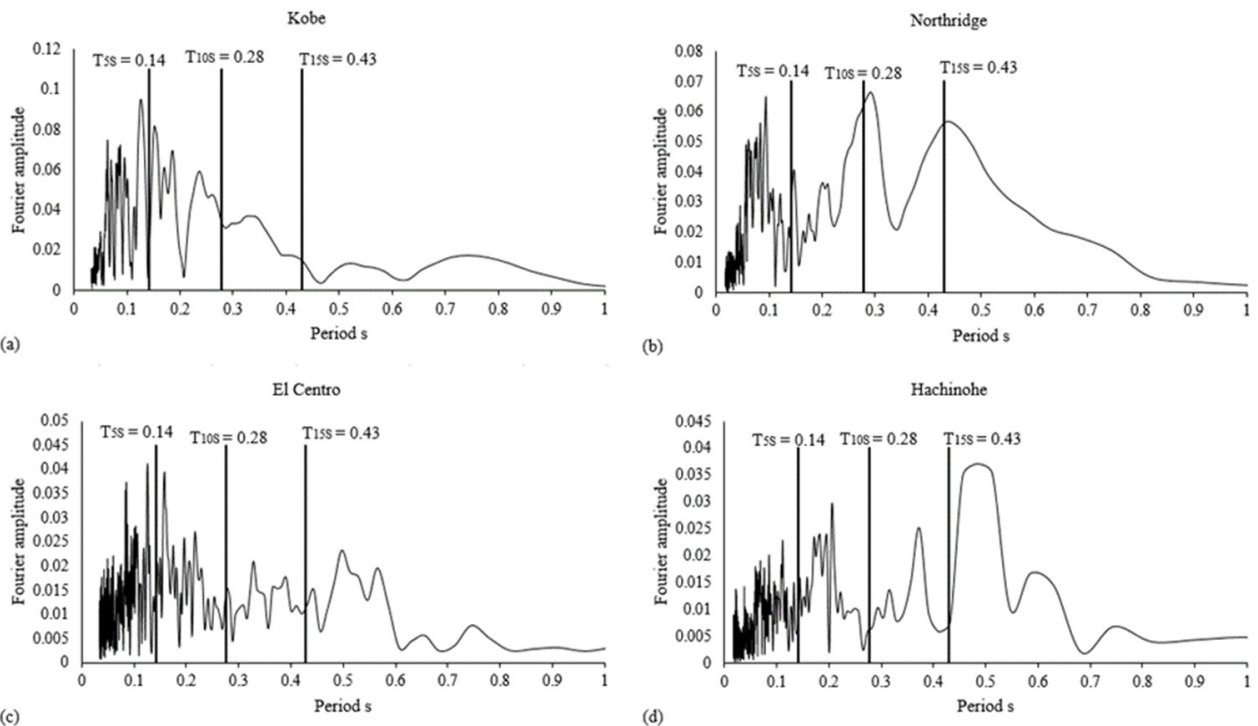

Figure 5: Fundamental periods of the 5-storey, 10-storey and 15-storey frames, and of Fourier spectrum of ground motion of (a) Scaled Kobe earthquake; (b) Scaled Northridge earthquake; (c) Scaled El Centro earthquake; and (d) scaled Hachinohe earthquake.

5-storey frame, by contrast, showed the highest relative displacement under the Kobe earthquake, at $15.4 \mathrm{~mm}$, and $9 \mathrm{~mm}, 5.3 \mathrm{~mm}$ and $3.5 \mathrm{~mm}$ for Northridge, El Centro and Hachinohe, respectively. 
Building response increases when the characteristic period of ground motion is close to a building's fundamental period [25], [30]. It is apparent from Fig. 5(b) that the dominant periods of the Northridge earthquake are close to the fundamental period of the 15-storey and 10 -storey models. Consequently, the response of these two models is amplified. On the other hand, the dominant period of the Kobe earthquake is close to the fundamental period of the 5-storey model, as shown in Fig. 5(a). Therefore, the response of 5-storey model is much higher for the Kobe earthquake than the Northridge earthquake. The dominant period of the El Centro and Hachinohe earthquakes are significantly far from the fundamental period of the three frames, as shown in Fig. 5(c) and 5(d).

\subsection{Required separation distance to avoid structural pounding}

Relative displacement is considered to be the most important parameter in structural pounding problems. If $u_{a}(t)$ and $u_{b}(t)$ are the displacement time histories of adjacent buildings "a" and " $b$ " at the potential pounding location (see Fig. 6) then the minimum separation gap required to prevent structural pounding $S$ is given by Lin and Weng [31]:

$$
S=\max \left[u_{a}(t)-u_{b}(t)\right]
$$

where $\max$ is the maximum value of the entire range of the relative displacement time history. Structural pounding may occur once the gap between potential pounding locations is less than $S$. In other words, pounding will occur when $u_{a}(t)-u_{b}(t)-S>0$. The minimum separation distance to avoid pounding, $u_{a}(t)-u_{b}(t)-S \leq 0$, between the 15 -storey and 10 -storey frames, the 15 -storey and 5-storey frames, and the 10-storey and 5-storey frames under the aforementioned scaled earthquakes are presented in Fig. 7. The minimum separation distances to preclude pounding for the 15-storey frame adjacent to the 10-storey frame are $16 \mathrm{~mm}, 15 \mathrm{~mm}, 32 \mathrm{~mm}$ and $66 \mathrm{~mm}$, under the influence of the four scaled earthquake accelerations of El Centro, Hachinohe, Kobe and Northridge, respectively. Furthermore, the minimum separation distance to avoid pounding between the 15-storey frame and the 5-storey frame are $10 \mathrm{~mm}, 10 \mathrm{~mm}, 15 \mathrm{~mm}$ and $20 \mathrm{~mm}$ for El Centro, Hachinohe Kobe and Northridge, respectively. Finally, the minimum separation distance to avoid pounding between the 10 -storey frame and the 5 -storey frame are $10 \mathrm{~mm}, 5 \mathrm{~mm}, 27 \mathrm{~mm}$ and $27 \mathrm{~mm}$ for El Centro, Hachinohe, Kobe and Northridge, respectively.

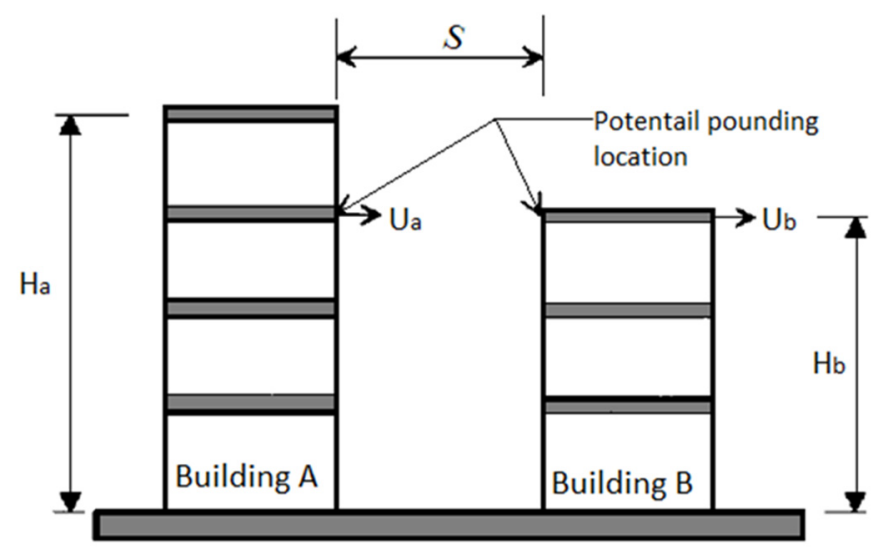

Figure 6: Potential pounding location between adjacent buildings with different heights. 

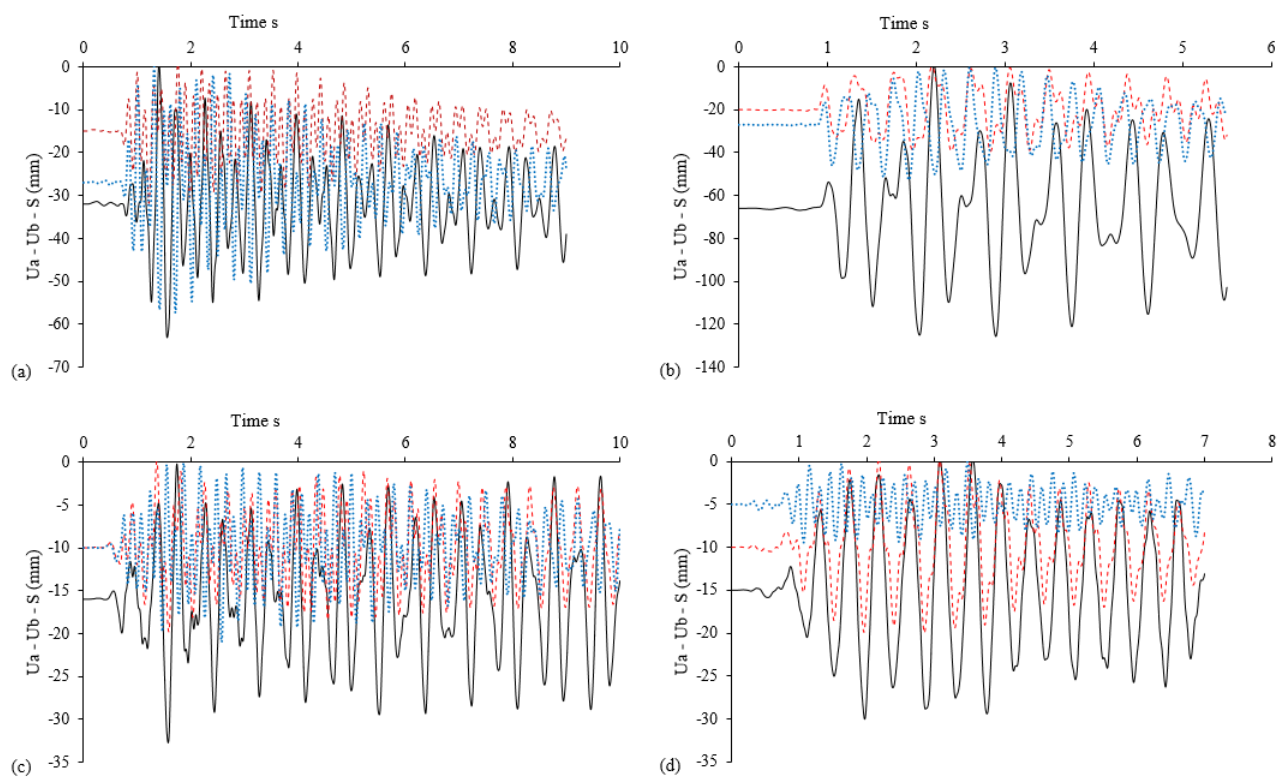

$$
\text { Legend } \quad-15 \mathrm{~S} \text { adjacent } 10 \mathrm{~S} \quad \cdots \cdots-15 \mathrm{~S} \text { adjacent } 5 \mathrm{~S} \quad \cdots \cdots \cdots \cdots \cdot 10 \mathrm{~N} \text { adjacent } 5 \mathrm{~S}
$$

Figure 7: Minimum separation distance to avoid pounding under (a) Scaled Kobe earthquake; (b) Scaled Northridge earthquake; (c) Scaled El Centro earthquake; and (d) Scaled Hachinohe earthquake.

\subsection{Code-specified separation distance}

The Australian Standards Earthquake Design Code AS1170.4-2007 requires that any building of earthquake design category II greater than $15 \mathrm{~m}$ in height, or any building of earthquake design category III, must be separated from adjacent structures or set back from an adjacent building boundary to avoid pounding. The minimum setback distance stipulated by the code is $1 \%$ of the structure height (see clauses 5.4.5 and 5.5.5 of AS1170.4-2007) [15]. By reading the code that a second building is adjacent to a first building, then the required separation gap is naturally assumed as the setback distance required for the second building. If both buildings have the same height, then it is clear that the required separation gap is $1 \%$ of the structure height.

However, if adjacent buildings have different heights then uncertainty naturally arises as to which structure height to use - the first building, already in place, or the second due for construction adjacent to it. Separation distance could be determined by either height [16].

The calculated required separation distances between two buildings using $1 \%$ height of either the taller or the shorter building are given in Table 3; these results will be compared with the numerical simulation results to evaluate the adequacy of code specifications. As previously discussed, building codes recommend separation gaps between adjacent buildings in order to avoid collision during earthquakes. ABS, SRSS and AS1170.4-2007 give equations to measure separation distance based on maximum lateral displacement (see eqns (1) and (2)) and height (see eqn (4)). Table 3 compares the code-required separation distance 
between adjacent buildings to avoid pounding and the numerical simulation results under four scaled earthquake ground motions. The tabulated results show that ABS is the safest rule to determine the required separation distance to avoid pounding between adjacent buildings. However, the ABS is conservative and overestimates the required separation distance to avoid pounding.

Table 3: Comparisons of separation distances to avoid pounding between adjacent buildings, under (a) near-field earthquake, in $\mathrm{mm}$; and (b) far-field earthquake, in $\mathrm{mm}$.

\begin{tabular}{|l|c|c|c|c|c|c|c|c|}
\hline \multirow{2}{*}{ (a) } & \multicolumn{4}{|c|}{ Kobe } & \multicolumn{4}{c|}{ Northridge } \\
\cline { 2 - 9 } & ABS & SRSS & Numerical & AS & ABS & SRSS & Numerical & AS \\
\hline 15S adjacent 10S & 38.5 & 29.0 & 32 & $15 / 10$ & 68.9 & 48.9 & 66 & $15 / 10$ \\
\hline 15S adjacent 5S & 25.1 & 18.2 & 15 & $15 / 5$ & 30.7 & 23.5 & 20 & $15 / 5$ \\
\hline 10S adjacent 5S & 32.9 & 23.3 & 27 & $10 / 5$ & 31.5 & 24.2 & 27 & $10 / 5$ \\
\hline
\end{tabular}

\begin{tabular}{|c|c|c|c|c|c|c|c|c|}
\hline \multirow{2}{*}{$(\mathrm{b})$} & \multicolumn{4}{|c|}{ El Centro } & \multicolumn{4}{c|}{ Hachinohe } \\
\cline { 2 - 9 } & ABS & SRSS & Numerical & AS & ABS & SRSS & Numerical & AS \\
\hline 15S adjacent 10S & 18.4 & 13.3 & 16 & $15 / 10$ & 19.1 & 15.7 & 15 & $15 / 10$ \\
\hline 15S adjacent 5S & 12.3 & 8.8 & 10 & $15 / 5$ & 13.4 & 10.5 & 10 & $15 / 5$ \\
\hline 10S adjacent 5S & 10.1 & 7.1 & 10 & $10 / 5$ & 6.1 & 4.4 & 5 & $10 / 5$ \\
\hline
\end{tabular}

Results from the SRSS rule are significantly and reasonably accurate (but not always conservative) and vary to conservative as well (but not as conservative as the ABS rule). These finding were also reported by [1], [11].

As illustrated in Table 3, separation distance calculated using $1 \%$ of the taller adjacent structure always underestimates the required separation distance to avoid pounding under near-field earthquakes except in one case; and in this case, the code-required separation distance of $15 \mathrm{~mm}$ ( $1 \%$ of the 15 -storey frame height) is adequate to preclude pounding between 15-storey and 5-storey frames under a scaled Kobe earthquake. On the other hand, separation distance calculated using $1 \%$ of the taller adjacent structure overestimates the required separation distance to avoid pounding under far-field earthquakes in most cases. However, if the separation distance is calculated as $1 \%$ of the shorter structure, this underestimates the required separation distance to avoid pounding under near-field and farfield earthquakes except in one case; and in this case, the code-required separation distance of $5 \mathrm{~mm}$ ( $1 \%$ of the 5 -storey frame height) is adequate to preclude pounding between 10 storey and 5-storey frames under a scaled Hachinohe earthquake.

These results indicate that the code specification is inadequate if the shorter building is used to estimate the required separation between adjacent structures under near-field and farfield earthquakes. By contrast, the code specification is adequate if the taller building is used to estimate the required separation between adjacent structures under far-field earthquakes only.

\section{CONCLUSION}

This article presents experimental and numerical investigations of the minimum separation distance to avoid pounding between adjacent buildings. The aim was to evaluate the adequacy of the minimum separation gap prescribed by AS1170.4 to avoid pounding of adjacent steelframe structures.

Shake table tests under the influence of four scaled earthquake acceleration records have been performed on the scale models, and the experimental measurements in terms of absolute 
acceleration time histories were determined. Afterwards, the numerical models of the constructed structural models were created, and fully non-linear time history dynamic analyses were performed under the influence of the four scaled earthquake acceleration records. Then, absolute acceleration time histories were determined and compared with the experimental measurements, which show good agreement. Subsequently, the numerical prediction in terms of relative displacement time histories were determined.

The results of this study conclude that the recommendations of the ABS are the safest method; however, ABS overestimates the required separation distance between adjacent buildings to avoid pounding. SRSS is significantly reasonably accurate, and not always conservative nor very conservative. It appears that the SRSS code-specified peak design displacement is the most appropriate method sufficient to avoid pounding or to minimise its effects. The required separation distance defined in AS1170.4-2007 is inadequate to avoid pounding when the shorter adjacent building is used under earthquake ground motion. The required separation distance defined in AS1170.4-2007 is adequate to avoid pounding only if the taller adjacent building is used under far-field earthquake ground motion.

The characteristics of ground motions whether far-field or near-field have a significant influence on the required separation gap to avoid pounding between adjacent buildings. It can be concluded that the minimum separation gap prescribed by AS1170.4 was based only on far-field earthquake ground motion, since Australia is a seismically inactive region. Appropriate gap distance for adjacent structures should be determined with regard to the characteristics of an expected earthquake along with the properties of structures.

\section{REFERENCES}

[1] Jeng, V., Kasai, K. \& Jagiasi, A. (eds), The separation to avoid seismic pounding. Proceedings of 10th World Conference on Earthquake Engineering, 1992.

[2] Rosenblueth, E. \& Meli, R., The 1985 Mexico earthquake. Concrete International, 8(5), pp. 23-34, 1986.

[3] Kasai, K. \& Maison, B.F., Building pounding damage during the 1989 Loma Prieta earthquake. Engineering Structures, 19(3), pp. 195-207, 1997.

[4] Anagnostopoulos, S. (ed), Building pounding re-examined: How serious a problem is it. 11th World Conference on Earthquake Engineering, Pergamon, Elsevier Science Oxford, UK, 1996.

[5] Jankowski, R. (ed), Comparison of numerical models of impact force for simulation of earthquake-induced structural pounding. International Conference on Computational Science, Springer, 2008.

[6] Jankowski, R. \& Mahmoud, S., Linking of adjacent three-storey buildings for mitigation of structural pounding during earthquakes. Bulletin of Earthquake Engineering, 14(11), pp. 3075-3097, 2016.

[7] Barros, R.C. \& Khatami, S.M. (eds), Seismic response effect of shear walls in reducing pounding risk of reinforced concrete buildings subjected to near-fault ground motions. Proceedings of the 15th World Conference on Earthquake Engineering, Lisbon, Portugal, 2012.

[8] Raheem, S.E.A., Mitigation measures for seismic pounding effects on adjacent buildings responses. 4th ECCOMAS Thematic Conference, Kos Island, Greece, 12-14 Jun. 2013.

[9] Richardson, A., Walsh, K. \& Abdullah, M., Closed-form design equations for controlling vibrations in connected structures. Journal of Earthquake Engineering, 17(5), pp. 699-719, 2013. 
[10] IBC, International Building Code, International Code Council: Country Club Hills, Illinois, 2009.

[11] Lopez-Garcia, D. \& Soong, T.T., Assessment of the separation necessary to prevent seismic pounding between linear structural systems. Probabilistic Engineering Mechanics, 24(2), pp. 210-223, 2009.

[12] Council, B.S.S. \& Council, A.T., NEHRP guidelines for the seismic rehabilitation of buildings. Federal Emergency Management Agency, 1997.

[13] NBCC, National Building Code of Canada, National Research Council: Ottawa, 2010.

[14] Eurocode8, Design of Structures for Earthquake Resistance - Part 1: General Rules, Seismic Actions and Rules for Buildings, European Committee for Standardization: Brussels, 2005.

[15] AS1170.4-2007, Structural Design Actions Part 4: Earthquake Actions in Australia, Standards Australia, 2007.

[16] Hao, H., Analysis of seismic pounding between adjacent buildings. Australian Journal of Structural Engineering, 16(3), pp. 208-225, 2015.

[17] Anagnostopoulos, S.A., Pounding of buildings in series during earthquakes. Earthquake Engineering \& Structural Dynamics, 16(3), pp. 443-456, 1988.

[18] Kasai, K., Jagiasi, A.R. \& Jeng, V., Inelastic vibration phase theory for seismic pounding mitigation. Journal of Structural Engineering, 122(10), pp. 1136-1146, 1996.

[19] Abdel Raheem, S.E., Mitigation measures for earthquake induced pounding effects on seismic performance of adjacent buildings. Bulletin of Earthquake Engineering, 12(4), pp. 1705-1724, 2014.

[20] Favvata, M.J., Minimum required separation gap for adjacent RC frames with potential inter-story seismic pounding. Engineering Structures, 152, pp. 643-659, 2017.

[21] Tabatabaiefar, S.H.R., Fatahi, B. \& Samali, B., Numerical and experimental investigations on seismic response of building frames under influence of soil-structure interaction. Advances in Structural Engineering, 17(1), pp. 109-130, 2014.

[22] Tabatabaiefar, H.R. \& Mansoury, B., Detail design, building and commissioning of tall building structural models for experimental shaking table tests. The Structural Design of Tall and Special Buildings, 25(8), pp. 357-374, 2016.

[23] Chopra, A., Dynamics of Structures, 3rd edn, Prentice Hall: New Jersey, 2007.

[24] Karamodin, A. \& Kazemi, H., Semi-active control of structures using neuro-predictive algorithm for MR dampers. Structural Control and Health Monitoring: The Official Journal of the International Association for Structural Control and Monitoring and of the European Association for the Control of Structures, 17(3), pp. 237-253, 2010.

[25] Yaghmaei-Sabegh, S. \& Jalali-Milani, N., Pounding force response spectrum for nearfield and far-field earthquakes. Scientia Iranica, 19(5), pp. 1236-1250, 2012.

[26] Hatzigeorgiou, G.D., Damping modification factors for SDOF systems subjected to near-fault, far-fault and artificial earthquakes. Earthquake Engineering \& Structural Dynamics, 39(11), pp. 1239-1258, 2010.

[27] Yaghmaei-Sabegh, S. \& Tsang, H., An updated study on near-fault ground motions of the 1978 Tabas, Iran, earthquake $(\mathrm{Mw}=7.4)$. Scientia Iranica, 18(4), pp. 895-905, 2011.

[28] Sap, C., Integrated software for structural analysis and design. Analysis Reference Manual, 2000.

[29] Jaradat, Y. \& Far, H., Optimum stiffness values for impact element models to determine pounding forces between adjacent buildings. Structural Engineering and Mechanics, 2020. 
[30] Abdel Raheem, S.E., Seismic pounding between adjacent building structures. Electronic Journal of Structural Engineering, 6, pp. 66-74, 2006.

[31] Lin, J.H. \& Weng, C.C., A study on seismic pounding probability of buildings in Taipei metropolitan area. Journal of the Chinese Institute of Engineers, 25(2), pp. 123$135,2002$. 